\title{
Drynaria Quercifolia Plant Extract as A Bone Regenerative Material in The Treatment of Periodontal Intrabony Defects: Clinical And Radiographic Assessment
}

\author{
Dr Varsha Pawar ${ }^{1}$, Dr K. T. Chandrashekar ${ }^{2}$, Dr Rohit Mishra ${ }^{3}$, Dr Vandana \\ Tripathi ${ }^{4}$ Dr Kaushal Tripathi ${ }^{5}$

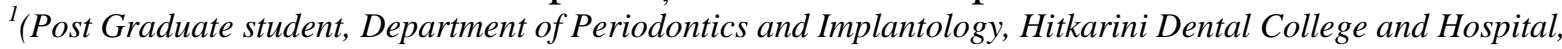 \\ India) \\ ${ }_{2}^{2}$ (Professor and Dean, Department of Periodontics and Implantology, Hitkarini Dental College and Hospital, \\ India) \\ ${ }^{3}$ (Professor, Department of Periodontics and Implantology, Hitkarini Dental College and Hospital, India) \\ ${ }^{4}$ (Associate Professor, Department of Periodontics and Implantology, Hitkarini Dental College and Hospital, \\ India) \\ ${ }^{5}$ (Post Graduate student, Department of Periodontics and Implantology, Hitkarini Dental College and Hospital, \\ India)
}

\begin{abstract}
:
Objective: The purpose of this clinical study was to assess the efficacy of Drynaria quercifolia plant (rhizome) extract as bone forming substitute in periodontal intraosseous defects.

Material and methods: Twenty patients with chronic periodontitis with intraosseous defects were selected for the study. The sites were randomly divided into control and experimental group. Control group was treated with open flap debridement (OFD) whereas the experimental group with OFD and placement of drynaria plant extract. Probing pocket depth (PPD), relative attachment level (RAL), radiographic evaluation including the depth of the bone defect and the percentage of bone defect fill were recorded for both the groups, at baseline, three and six months.

Results: The control and experimental groups from baseline to six months showed the PPD reduction by 3.2 $\mathrm{mm}(45.71 \%)$ and $4.6 \mathrm{~mm}(63.01 \%)$, respectively. RAL gain by $3.9 \mathrm{~mm}(30.47 \%)$ and $5.5 \mathrm{~mm}(42.97 \%)$ ), respectively; gain in bone fill level was $2.22 \pm 0.6(29.23 \%)$ and $3.71 \pm 0.54 \mathrm{~mm}(44.97 \%)$, respectively.

Conclusion: The Probing pocket depth reduction and relative attachment level gain after six months were more for the experimental group as compared to the control group and the difference was statistically significant.
\end{abstract}

Keywords : Alkaline phosphatase, Bone morphogenic proteins, Intrabony defects, Naringin, Rhizome

\section{Introduction}

Periodontal disease is an all-encompassing term related to inflammatory disorders of the periodontium. The regenerative goal of periodontal therapy is to restore periodontal tissues affected by disease to their original architectural form and function. This requires regeneration of the gingival connective tissues destroyed by inflammation, formation of cementum, restoration of lost bone and re-establishment of connective tissue fiber attachment to the previously diseased root surfaces.

Periodontal regeneration is a complex multifactorial process involving biologic events like cell adhesion, migration, proliferation, and differentiation in an orchestrated sequence. Periodontal regenerative procedures include soft tissue grafts, bone grafts, root biomodifications, guided tissue regeneration, and combinations of these procedures. Tissue engineering based approaches and stem cells have emerged as prospective alternatives to conventional treatments. However, few of these techniques have shown predictable results for periodontium regeneration; therefore, it remains a challenge to rebuild functional periodontal tissues. ${ }^{\text {. }}$

However, the risk of transmission of infection and immunologic reactions prompted scientists to continue search for new materials that regenerate bone, especially from plant extracts. Plants used in traditional health care have become the main source of drug discovery and development. ${ }^{[2]}$

Traditional herbal formulae have been developed to promote bone healing in fractures. Referred to as "bone knitting herbs", these specialized formulae speed up bone healing in fractures. Modern research has identified the physiological actions of traditional bone-knitting herbs which work to rebuild bone tissues. ${ }^{[3]}$

Drynaria quercifolia (L) J. Smith (Polypodiaceae), commonly known as "Oak Leaf Fern", is found in Bangladesh, India, Pakistan, North America and Africa [ Fig.1(a)]. Traditionally, the soup prepared from the rhizome of D.quercifolia is very popular among tribes of Eastern Ghats of Tamil Nadu (India) and is known for its remedial effects for rheumatic complaints. The fern drynaria quercifolia rhizome is also used by local tribes 
in the rain forests of Western Ghats of Maharashtra (India), where the rhizome is ground into a paste and is used to treat diarrhea, typhoid, cholera, chronic jaundice, fever, headache, skin diseases and fractures. The extract of rhizome of drynaria which contains flavonoid and triterpenoid compounds has been shown to increase bone cell viability, intracellular total proteins, alkaline phosphatase and acid phosphatase. Therefore, the purpose of this prospective, randomized controlled clinical trial is to evaluate the bone forming ability of drynaria quercifolia plant extract in the treatment of periodontal osseous defects by clinical and radiological analysis.

\subsection{Study design}

\section{Material And Methods}

Prospective randomised controlled trial

\subsection{Source of data and patient selection}

The study population of twenty subjects in 30-55 years of age, with chronic periodontitis and presence of intrabony defects were selected randomly from the outpatient section, Department of Periodontics and Implantology, Hitkarini Dental College and Hospital, Jabalpur, Madhya Pradesh, India. The present study was presented and approved by the ethical committee of Hitkarini Dental College and Hospital, Jabalpur (India). A written informed consent form explaining the nature of the study and surgical procedure was signed by all the participating patients. Phase I therapy was followed by maintenance phase. Patients were re-evaluated after four weeks of phase-I therapy.

\subsubsection{Inclusion criteria:}

1. Patients diagnosed as having chronic periodontitis with periodontal pockets of probing depth $\geq 5 \mathrm{~mm}$ with radiographic evidence of vertical bone loss.

2. Patients with good general health, without any history of systemic disease or under medication.

3. Patients who maintained good oral hygiene.

\subsubsection{Exclusion criteria:}

1. Smokers

2. Pregnant women and lactating mothers.

\subsection{Material used}

The plant was procured from Udhagamandalam, Ooty, Tamil Nadu (India). The raw material collected was rhizome of drynaria plant which was shade dried and sent to Centre of Food Technology, University of Allahabad, Allahabad, U.P. (India) for processing. ${ }^{[6]}$

There were four materials used for extraction viz. petroleum ether, ethanol, methanol and chloroform, among which ethanol gave maximum extract [Fig. 1(b)]. After the extraction process, the extract was dried using rotary vacuum evaporator and as a result 12 grams w/w out of 100 grams was obtained. The extraction process was carried out for 17 hours and evaporated for 3 days.

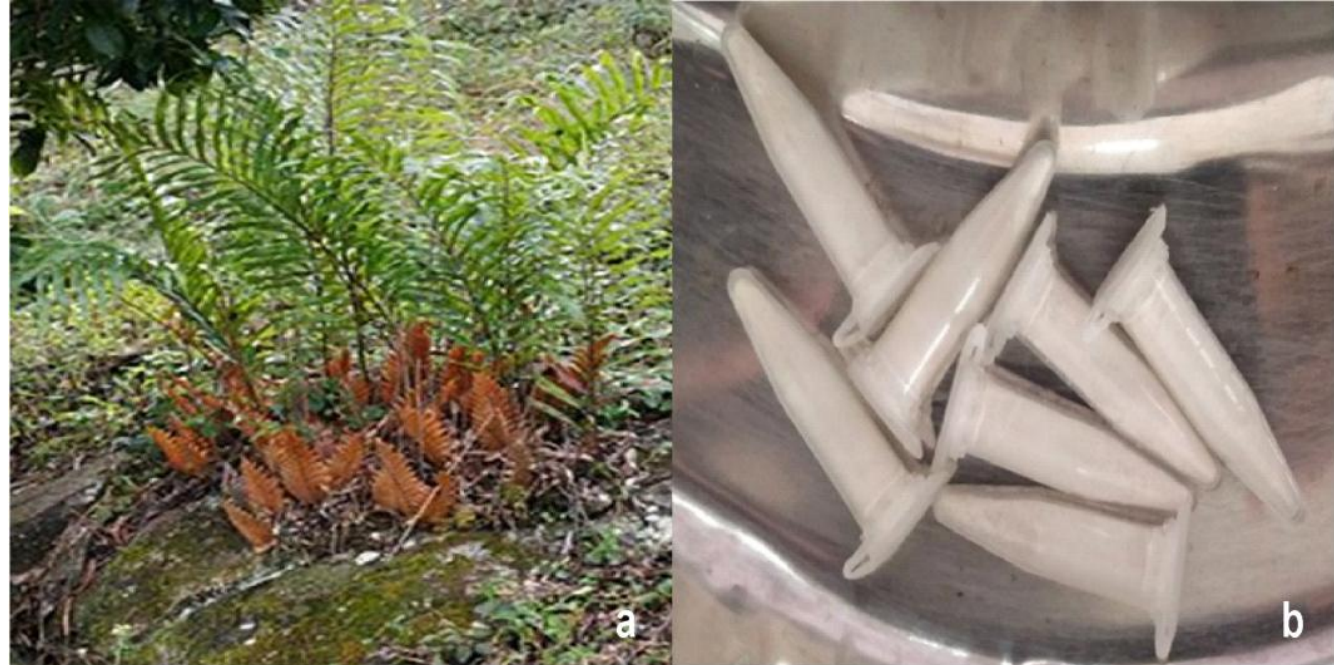

Fig : 1(a) Drynaria quercifolia plant (b). Prepared rhizome extract

The resulting extract was the ethanolic extract and it was formulated in gel form to be used as a bone fill material in periodontal intrabony defects.

DOI: 10.9790/0853-1603069399 $\quad$ www.iosrjournals.org $\quad 94 \mid$ Page




\subsection{Patient groups}

Selected sites were randomly (toss of a coin) allocated to two groups. In control group, open flap debridement was done, whereas in experimental group, open flap debridement was followed by the placement of drynaria plant extract. Recall appointments were made at one week, one month, three months and six months.

\subsection{Clinical parameters}

Baseline recording of clinical parameters including gingival index, probing pocket depth and clinical attachment loss was done using a UNC-15 probe and occlusal stent.

\subsection{Laboratory investigations}

The selected patients were subjected to routine blood examination to record hemoglobin \%, bleeding time, clotting time, total leucocyte count, differential leucocyte count and random blood sugar. An ELISA test for HIV and Hepatitis screening were also recommended.

\subsection{Radiographic parameters}

Intraoral periapical radiograph of each selected site using long cone paralleling technique was exposed before treatment and after six months.

\subsection{Surgical procedure}

After adequate local anesthesia, crevicular incisions were made. The defect site was exposed by reflection of a full-thickness mucoperiosteal flap, followed by debridement of the diseased granulation tissue, through root planing and irrigation with normal saline. In control group; debridement of diseased granulation tissue was done. In experimental group, after debridement the defect was filled with drynaria plant extract with the help of cumine scaler. The material was placed from the base of the defect coronally to the level of the crest of the osseous walls.

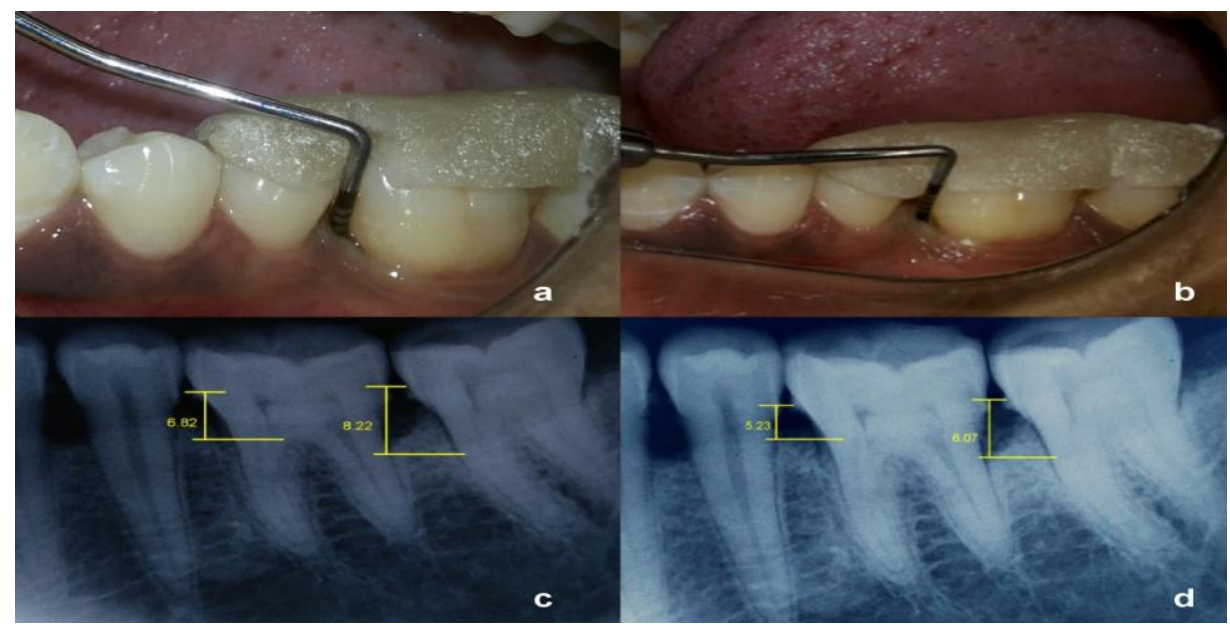

Fig : 2 (a). Measurement of bone defect at control group site using UNC-15 probe in between 35, 36 at baseline; (b). Measurement of bone defect at control group site using UNC-15 probe in between 35, 36 after six months; (c). IOPA x-ray of control group site at baseline; (d) IOPA x ray after six months

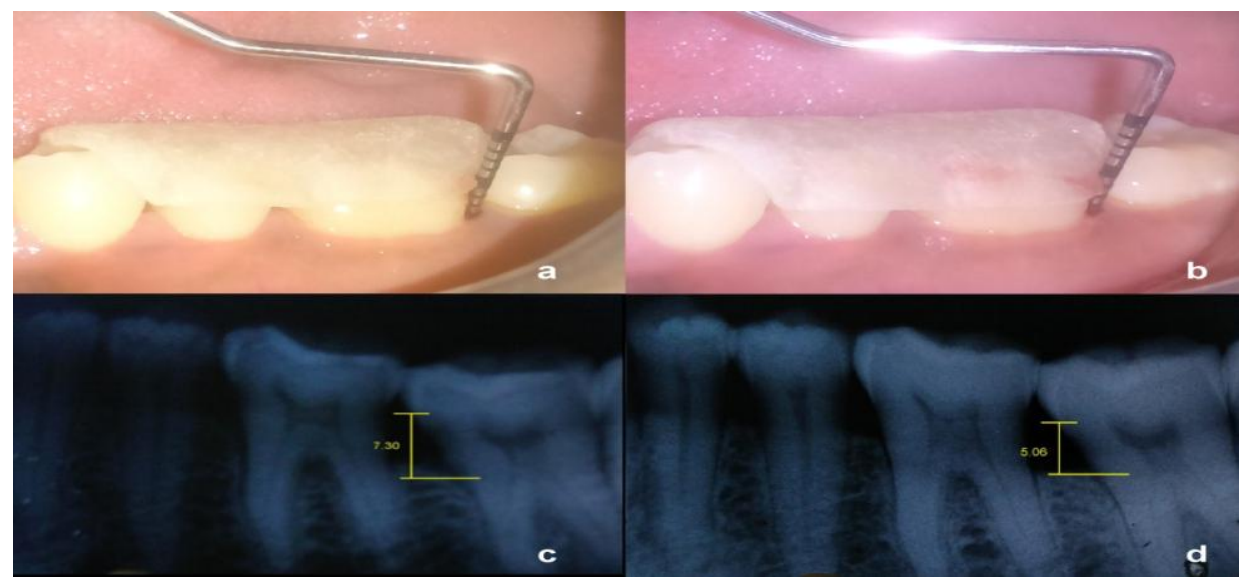

Fig : 3 (a). Measurement of bone defect at experimental group site using UNC-15 probe in between 36,37 at baseline; 
(b). Measurement of bone defect at experimental group site using UNC-15 probe in between 36, 37 after six months; (c). IOPA x-ray of experimental group site at baseline; (d) IOPA x ray after six months

The mucoperiosteal flaps were repositioned and secured in place using black braided (3-0) interrupted silk sutures to obtain primary closure of the interdental space and was protected with a periodontal dressing. All patients were prescribed analgesics for five days.

Post one week, the dressing and sutures were removed and surgical site was irrigated thoroughly with saline. Symptoms regarding discomfort, pain, and sensitivity were asked from the patient. Patients were instructed to rinse with chlorhexidine $(0.2 \%)$ mouthwash twice daily for another week. Recall appointments were made at 3 months and 6 months intervals. At each visit, oral hygiene instructions were reinforced and the surgical sites were professionally irrigated with normal saline.

At the end of three months and six months post therapy, patients were evaluated clinically and radiographically. Clinical parameters (plaque index(PI), gingival index(GI), probing pocket depth(PPD), relative attachment level(RAL)) and radiographic measurements were repeated for both control and experimental group sites similar to previous presurgical measurements.

\section{Results}

In the present clinical study both the treatment modalities showed a reduction in the mean P I, GI, PPD, and gain in RALand bone fill.

\subsection{Plaque Index}

Comparative analysis of control and experimental group at baseline revealed mean scores of $1.91 \pm$ 0.61 and $1.89 \pm 0.58$ respectively. After SRP, the value was $0.68 \pm 0.21$ for control and $0.70 \pm 0.19$ for experimental group. At six months post operatively, the values showed a mean of $1.07 \pm 0.51$ for control and $1.14 \pm 0.52$ for experimental group with ' $t$ ' value of 0.301 indicating no statistically significant difference.

Table 1: Mean Plaque Index before and after treatment

\begin{tabular}{|c|c|c|c|c|c|}
\hline \multirow{5}{*}{ Plaque index } & $\begin{array}{c}\text { Time } \\
\text { interval }\end{array}$ & \multicolumn{2}{|c|}{ Control group } & \multicolumn{2}{c|}{ Experimental group } \\
\cline { 2 - 6 } & & (Mean \pm SD) & $\begin{array}{c}\% \text { Change from } \\
\text { baseline }\end{array}$ & (Mean \pm SD) & $\begin{array}{c}\text { \% Change } \\
\text { from baseline }\end{array}$ \\
\cline { 2 - 6 } & Baseline & $1.91 \pm 0.61$ & & $1.89 \pm 0.58$ & \\
\cline { 2 - 6 } & $\begin{array}{c}\text { After } \\
\text { scaling }\end{array}$ & $0.68 \pm 0.21$ & $64.10 \%$ & $0.70 \pm 0.19$ & $72.30 \%$ \\
\cline { 2 - 6 } & 3 months & $1.01 \pm 0.42$ & $48.50 \%$ & $1.04 \pm 0.38$ & $63.40 \%$ \\
\cline { 2 - 6 } & 6 months & $1.07 \pm 0.51$ & $52.30 \%$ & $1.14 \pm 0.52$ & $54.30 \%$ \\
\hline
\end{tabular}

\subsection{Gingival Index}

The mean scores of gingival index of control and experimental group at baseline were 1.32 \pm 0.0 .24$ and $1.36 \pm 0.25$ respectively. After six months, the values showed a mean of $0.68 \pm 0.29$ for control and $0.65 \pm$ 0.22 for experimental group with a ' $t$ ' value of 0.25 indicating no statistically significant difference between the two groups.

Table : 2 Mean Gingival Index before and after treatment

\begin{tabular}{|c|c|c|c|c|c|}
\hline \multirow{6}{*}{ Gingival index } & Time interval & \multicolumn{2}{|c|}{ Control group } & \multicolumn{2}{|c|}{ Experimental group } \\
\hline & & $(\mathrm{Mean} \pm \mathrm{SD})$ & $\begin{array}{c}\% \text { Change from } \\
\text { baseline }\end{array}$ & $\begin{array}{c}\text { Mean } \pm \text { SD } \\
\text { ) }\end{array}$ & $\begin{array}{l}\text { \% Change } \\
\text { from } \\
\text { baseline }\end{array}$ \\
\hline & Baseline & $1.32 \pm 0.24$ & & $1.36 \pm 0.25$ & \\
\hline & After scaling & $0.63 \pm 0.37$ & $52.20 \%$ & $0.63 \pm 0.31$ & $50.70 \%$ \\
\hline & 3 months & $0.68 \pm 0.28$ & $58.80 \%$ & $0.75 \pm 0.31$ & $59.60 \%$ \\
\hline & 6 months & $0.68 \pm 0.29$ & $57.30 \%$ & $0.65 \pm 0.22$ & $66.60 \%$ \\
\hline
\end{tabular}

\subsection{Probing Pocket Depth}

Comparative analysis of control and experimental group at baseline revealed a score of $7.0 \pm 1.05$ and $7.3 \pm 1.15$ [Fig. 2(a), 3(a)]. After six months, the values showed a mean of $3.8 \pm 1.39$ for control and $4.7 \pm$ 0.48 for experimental group with a ' $t$ ' value of 2.357 indicating statistically significant difference [Fig. 2(b), $3(\mathrm{~b})]$

Table : 3 Probing Pocket Depth score for Control group (OFD) and Experimental group (OFD + Drynaria) 


\begin{tabular}{|c|c|c|c|c|c|}
\hline \multirow{4}{*}{} & Time interval & \multicolumn{2}{|c|}{ Control group } & \multicolumn{2}{c|}{ Experimental group } \\
\cline { 2 - 6 } & & Mean \pm SD) & $\begin{array}{c}\text { \% Change from } \\
\text { baseline }\end{array}$ & $\begin{array}{c}\text { (Mean } \pm \text { S } \\
\text { D) }\end{array}$ & $\begin{array}{c}\text { \% Change from } \\
\text { baseline }\end{array}$ \\
\cline { 2 - 6 } $\begin{array}{c}\text { Pocket } \\
\text { probing } \\
\text { depth }\end{array}$ & Baseline & $7.0 \pm 1.05$ & & $7.3 \pm 1.15$ & \\
\cline { 2 - 6 } & After scaling & $5.9 \pm 0.73$ & $25.70 \%$ & $5.9 \pm 0.74$ & $29.12 \%$ \\
\cline { 2 - 6 } & 3 months & $4.5 \pm 0.52$ & $26.71 \%$ & $4.0 \pm 1.24$ & $32.20 \%$ \\
\cline { 2 - 6 } & 6 months & $3.8 \pm 1.39$ & $35.5 \%$ & $2.7 \pm 0.48$ & $42.53 \%$ \\
\hline
\end{tabular}

\subsection{Relative attachment level}

Comparative analysis of control and experimental group at baseline revealed a score of $12.8 \pm 0.78$ and $12.8 \pm 0.78$ respectively. After six months, the values showed a mean of $8.9 \pm 0.87$ for control group and $7.3 \pm$ 1.06 for experimental group with ' $t$ ' value of 3.681 indicating statistically significant difference.

Table : 4 Relative attachment level score for Control group (OFD) and Experimental group (OFD + Drynaria)

\begin{tabular}{|c|c|c|c|c|c|}
\hline \multirow{5}{*}{$\begin{array}{l}\text { Relative } \\
\text { attachment } \\
\text { level }\end{array}$} & Time interval & \multicolumn{2}{|c|}{ Control group } & \multicolumn{2}{|c|}{ Experimental group } \\
\hline & & $(\mathrm{Mean} \pm \mathrm{SD})$ & $\begin{array}{c}\% \text { Change from } \\
\text { baseline }\end{array}$ & $\begin{array}{c}(\text { Mean } \pm \text { SD } \\
)\end{array}$ & $\begin{array}{c}\text { \% Change from } \\
\text { baseline }\end{array}$ \\
\hline & Baseline & $12.8 \pm .78$ & & $12.8 \pm .78$ & \\
\hline & After scaling & $10.9 \pm 1.28$ & & $5.9 \pm 0.74$ & \\
\hline & 3 months & $8.6 \pm 0.84$ & $30.49 \%$ & $8.4 \pm 0.51$ & $34.38 \%$ \\
\hline & 6 months & $8.9 \pm 0.87$ & $32.81 \%$ & $7.3 \pm 1.06$ & $42.97 \%$ \\
\hline
\end{tabular}

\subsection{Bone fill measurements using radiographs}

When compared between the groups, control group had less bone fill [Fig. 2(c,d)] than experimental group [Fig. 3(c,d)] which was also statistically significant.

Table 5: Mean radiographic defect fill before and after treatment

\begin{tabular}{|c|c|c|c|c|c|}
\hline \multirow{4}{*}{$\begin{array}{l}\text { Radiographic } \\
\text { assessment }\end{array}$} & Time interval & \multicolumn{2}{|c|}{ Control group } & \multicolumn{2}{|c|}{ Experimental group } \\
\hline & & $($ Mean \pm SD) & $\begin{array}{c}\text { \% Change from } \\
\text { baseline }\end{array}$ & $\begin{array}{c}\text { (Mean } \pm \\
\text { SD) }\end{array}$ & $\begin{array}{c}\text { \% Change from } \\
\text { baseline }\end{array}$ \\
\hline & Baseline & $7.63 \pm 1.05$ & & $\begin{array}{l}8.25 \pm 1.0 \\
3\end{array}$ & \\
\hline & 6 months & $5.41 \pm 1.11$ & $29.23 \%$ & $\begin{array}{c}4.54 \pm 0.4 \\
9\end{array}$ & $44.97 \%$ \\
\hline
\end{tabular}

Graph 1: Bone fill measurements using radiographs

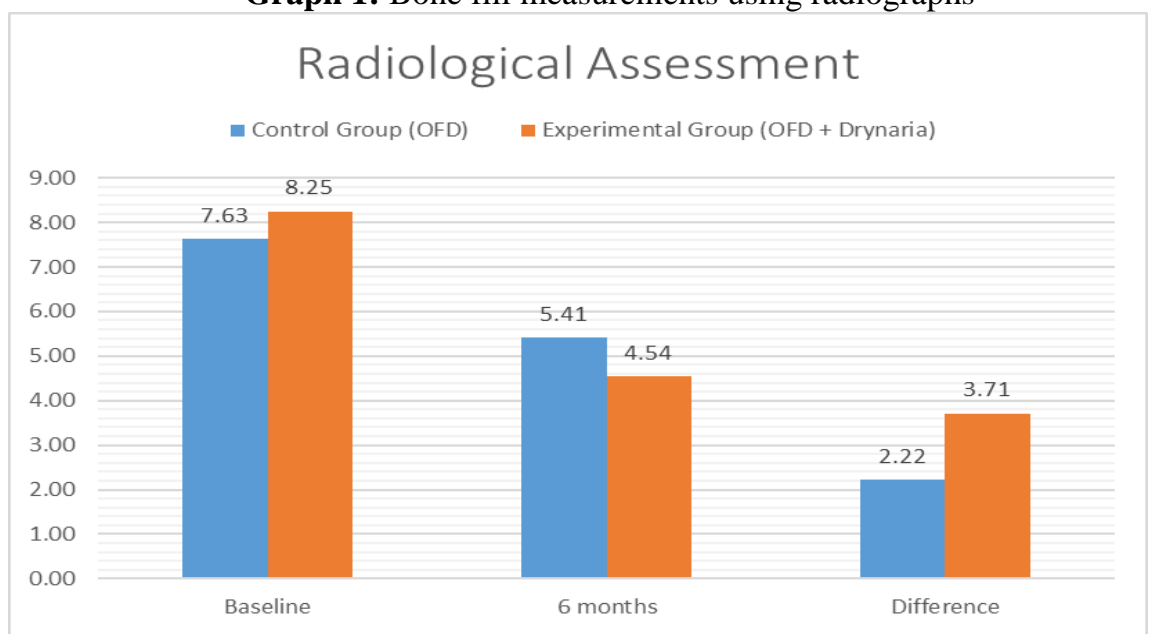

\section{Discussion}

The complete or predictable restoration of the periodontium following infection or trauma remains a critical objective in periodontics. ${ }^{[8]}$ Bone replacement grafts remain among the most widely used therapeutic strategies for the correction of periodontal osseous defects. A wide range of graft materials have been applied 
and evaluated clinically, radiographically and histologically, including autografts, allografts, xenografts, and synthetic/semi-synthetic materials. ${ }^{[9]}$

Bone replacement grafts (bone grafts and bone graft substitutes) provide a structural framework for clot development, maturation and remodelling that supports bone formation in osseous defects. Ideal characteristics of a bone graft are: nontoxic, non-antigenic, resistant to infection, no root resorption or ankylosis, strong and resilient, easily adaptable, ready and sufficiently available, minimal surgical procedure, stimulate new attachment and be able to trigger osteogenesis, cementogenesis and formation of a functional periodontal ligament. ${ }^{[10]}$

Modern research has identified the physiological actions by which traditional bone-knitting herbs work to rebuild bone tissues. Over time, a large body of contemporary research has focused on one particular herb that is particularly effective at restoring bone loss arising from periodontal disease. The herb, Drynaria, is referred to in China as GuSuiBu, literally meaning "mend broken bones" ${ }^{[11]}$ Various phytoconstituents like 3,4dihydroxybenzoic acid, fridelin, epifriedelinol, coumarins has been isolated from the plant and these bioactive compounds responsible for its antidermatophytic, antimicrobial, anti-lipidperoxidative, antiulcer, antipyretic, anti-arthritis, anti-urolithiatic and thrombolytic activities. ${ }^{[12]}$

The Drynaria quercifolia rhizome extract is known to increase the alkaline phosphatase (ALP) activity and accelerate synthesis of proteoglycans. ${ }^{[13]}$ The active components of the plant mainly naringin increases bone formation more than that of the growth factors like bone morphogenic proteins (BMPs) ${ }^{[14]}$ It is important to speculate as to the mechanism of action of Drynaria quercifolia in the process of osteogenesis when used as a graft material. It has a positive effect on promoting calcification as well as ALP activity, suggesting an anabolic effect on bone calcifications in vitro. ${ }^{[15]}$

Using drynaria plant extract in our study, there was evidence of reduction in probing pocket depth and gain in relative attachment level in both the groups from baseline to three and six months. When compared between the groups, bone fill in the experimental group was more than the control group, and this difference was statistically significant.

The osteoinductive ability shown when used as a graft material, suggests that it might have a positive effect in regulating the host tissues. Such an effect could be due to angiogenesis or osteogenesis through the upregulation of the expression of osteogenic factors.

On the basis of the accumulated evidence and assessment of the soft and hard tissue parameters we can conclude that the significant bone regenerating ability of the rhizome extract can herbally induce bone formation in periodontal intrabony defects.

\section{Conclusion}

In this study, we demonstrated that Drynaria quercifolia rhizome extract has potential regenerative effects on the bone cells. One of the major effects of plant extract on the bone cells is probably mediated by its effect on the osteclasts attachment. It is also known to increase the alkaline phosphatase (ALP) activity and accelerated synthesis of proteoglycans. On the basis of the accumulated evidence and assessment of the soft and hard tissue parameters we can conclude that the rhizome extract of Drynaria quercifolia plant can be used as a herbal bone formative in periodontal intrabony defects.

\section{Acknowledgement}

I would like to sincerely thank my parents Mr. Vinod Choubey, Mrs. Rekha Choubey, Mr. S. S. Pawar and Mrs. Meena Pawar for their support and motivation and my husband Mr. Rishi Pawar for his perseverance and encouragement. I would also like to mention of Dr. S. Rajan (Field Botanist, Survey of medicinal plants and collection unit, Tamil Nadu), Mr. A. Ghosal (Pansila Pharmaceuticals Ltd., Jabalpur) and Dr. Madhuresh Dwivedi (Assistant Professor, Centre of Food technology, Allahabad University, Uttar Pradesh) who helped me with the procurement and processing of the plant.

\section{References}

[1]. W. V. Giannobile. The Potential Role Of Growth And Differentiation Factors In Periodontal Regeneration. J Periodontol, Volume 67, 1996, P.545e 53

[2]. A. Atanasov. Discovery And Resupply Of Pharmacologicallyactive Plant Derived Natural Products: A Review. Biotechnol Adv. 2015 Dec; 33(8): 1582-1614.

[3]. J. English. Drynaria - Benefits Of Unique Bone Building Herb For Gingivitis And Osteoporosis. Nutritonreview.Org. July 17, 2014

[4]. S. Saravanan. Ameliorative Effect Of Drynaria Quercifolia (L.) J. Sm., An Ethnomedicinal Plant,In Arthritic Animals. Elsevier Ltd. 2012 October; 15(2013).

[5]. Wong Rw, Ricky W. The Effects Of Rhizoma Curculiginis And Rhizoma Drynariae Extracts On Bones. Chin Med. 2007 December; 19(2).

[6]. M.Kandhasamy, K. Arunachalam. Drynaria Quercifolia (L.) J. Sm : A Potential Resource For Antibacterial Activity. African Journal Of Microbiology Research Vol. 2 Pp. 202-205, August 2008.

[7]. Ahmed Mn, Gowan M. Clinical Appraisals And Phytochemical Potential Of Ethnomedicinalpteridophyte: Drynariaquercifolia(L.) J. Smith (Polypodiaceae). Pharmacologyonline. 2015 April; 1. 
[8]. Garrett S. Periodontal Regeneration Around Natural Teeth. Ann Periodontol. 1996 November; 1.

[9]. Reynolds Ma, Reidy Me, Branch-Mays Gl. Regeneration Of Periodontal Tissue : Bone Replacement Grafts. Dent Clin North Am. $2010 \mathrm{Jan} ; 54(1): 55-71$

[10]. Rosenberg E, Rose Lf. Biologic And Clinical Considerations For Autografts And Allografts In Periodontal Regeneration Therapy. Dent Clin North Am 1998;42:467 - 490.

[11]. Wang Y, Wang X, Zhang L, Jin S, Zhang J. Effects Of Traditional Chinese Medicine On Bone Remodeling During Orthodontic Tooth Movement. J Ethnopharmacol. 2012 June; 141(2).

[12]. Kamboj P, Kalia A N. Hepatoprotective Effect Of Drynaria Quercifolia Fronds Hydroalcoholic Extract And Isolated Constituent Against $\mathrm{Ccl}_{4}$ Induced Hepatocellular Damage. British Journal Of Pharmaceutical Research, 3(4): 563 - 578, 2013.

[13]. Jiang J, Ding Y. Effects Of Drynaria Fortunei Naringin On Proliferation, Alkaline Phosphatase Activity Of Human Periodontal Ligament Cells. West China Journal Of Stomatology; 2009 October; 27.

[14]. Zhanwang X, Nianhu . Naringin Promotes Osteoblast Differentiation And Effectively Reverses Ovariectomy Associated Osteoporosis. Journal Of Orthopaedic Science. 2013 May; 18(3).

[15]. Shu X, Zhu D. Effects Of Drynaria Total Flavonoid On Osteogenic Differentiation Of Bone Marrow Mesenchymal Stem Cells At Different Glucose Concentrations: Experiment With Rats. Chin J Integr Med. 2010 October; 90(38). 